DO NOT DISTRIBUTE. COPY OF MANUSCRIPT UNDER REVIEW.

\title{
System Tradeoffs in Siting a Solar Photovoltaic Material Recovery Infrastructure
}

Michele Goe $^{1}$, Gabrielle Gaustad ${ }^{1}$, and Brian Tomaszewski ${ }^{2}$

${ }^{1}$ Golisano Institute for Sustainability,

2 Department of Information Sciences and Technologies,

Rochester Institute of Technology, 190 Lomb Memorial Drive, Rochester, NY 14623 USA

\begin{abstract}
The consumption and disposal of rare and hazardous metals contained in electronics and emerging technologies such as photovoltaics increases the material complexity of the municipal waste stream. Developing effective waste policies and material recovery systems is required to inhibit landfilling of valuable and finite resources. This work developed a siting and waste infrastructure configuration model to inform the management and recovery of end-of-life photovoltaics. This model solves the siting and waste location-allocation problem for a New York State case study by combining multi-criteria decision methods with spatial tools, however this methodology is generalizable to any geographic area. For the case study, the results indicate that PV installations are spatially statistically significant (i.e., clustered). At least 9 sites, which are co-located with landfills and current MRFs, were 'highly' suitable for siting according to our criteria. After combining criteria in an average weighted sum, $86 \%$ of the study area was deemed unsuitable for siting while less than $5 \%$ is characterized as highly suitable. This method implicitly prioritized social and environmental concerns and therefore, these concerns accounted for the majority of siting decisions. As we increased the priority of economic criteria, the likelihood of siting near ecologically sensitive areas such as coastline or socially vulnerable areas such as urban centers increased. The sensitivity of infrastructure configurations to land use and waste policy are analyzed. The location allocation model results suggest current tip fees are insufficient to avoid landfilling of photovoltaics. Scenarios where tip fees were increased showed model results where facilities decide to adopt limited recycling technologies that bypass compositionally complex materials; a result with strong implications for global PV installations as well as other waste streams. We suggest a multi-pronged approach that lowers technology cost, imposes a minimum collection rate, and implements higher tip fees would encourage
\end{abstract}


DO NOT DISTRIBUTE. COPY OF MANUSCRIPT UNDER REVIEW.

exhaustive material recovery for solar photovoltaic modules at end-of-life, beyond New York State. These results have important implications for policy makers and waste managers especially in locations where there is rapid adoption of renewable energy technologies.

Keywords: material recovery, recycling, geographic information systems, photovoltaics, municipal solid waste, waste management

\section{Introduction}

Despite the steady increase in recycling rates over the last 50 years, $54 \%$ of municipal solid waste (MSW) generated in the U.S. ends up in landfills(National Renewable Energy Laboratory, 2014; US Environmental Protection Agency, 2009). The majority (79\%) of MSW generation is benign and relatively low economic value bulk materials like plastic, glass, paper containers, yard trimmings and food scraps. However, the rapid increase in the consumption of products that contain both valuable and hazardous materials could increase the complexity of MSW. The increase in consumption of valuable and hazardous materials is a global phenomenon that has set off long-term material scarcity and waste management concerns (Charabi and Gastli, 2011; Y. Choi et al., 2011; Funabashi, 2011; Graedel, 2011; Hofierka and Kaňuk, 2009; Huld and Šúri, 2003; Peiró et al., 2013; Ramirez-Rosado et al., 2011; Tiba et al., 2010; Vardimon, 2011). Recognizing the negative social, economic and environmental impacts of landfilling (Bevc et al., 2007; Ham et al., 2013; Schelly, 2014), policy is moving in the direction of waste reduction and waste elimination strategies that center around material recovery. This is especially the case for waste electronics and electrical equipment (WEEE) where state and national policymakers have recognized the potential of material recovery to address this compositionally complex waste stream. For example, at least fifteen states have landfill bans on cathode ray tube (CRT) monitors and other WEEE, mainly because they contain lead. Although CRT monitors are an obsolete technology whose production peaked 15 years ago, its waste policy initiatives have only been enacted recently (earliest in 2009). WEEE landfill bans (which act as mandatory recycling policies) have been plagued by illegal waste exporting practices, negative environmental impacts of informal recycling, and difficulty integrating with the current MSW infrastructure (Li et al., 
DO NOT DISTRIBUTE. COPY OF MANUSCRIPT UNDER REVIEW.

2011; Nnorom and Osibanjo, 2008; Noll et al., 2014; Osibanjo and Nnorom, 2007; Rai and McAndrews, 2012; Robinson et al., 2013; United States Internal Trade Commission, 2013).

These challenges are not unique to WEEE. All emerging technologies, especially those with potentially high volumes and that make use of valuable, hazardous, and finite material resources, have uncertain material recovery routes. This work uses photovoltaics (PV) as a case study to demonstrate a methodology for assessing siting tradeoffs of emerging technologies. Photovoltaics have experienced rapid growth of nearly $100 \%$ per year and have not yet reached peak production. Despite this rapid adoption, no end-of-life (EoL) policy has been developed in the US. Mature silicon and thin-film PV currently produced contain hazardous materials such as arsenic, zinc, and cadmium and valuable materials such as indium, gallium, and tellurium shown in Supplemental. Due to the long lifetimes expected (i.e. greater than 20 years), lack of US EoL policy, and uncertain secondary processing technology, a looming waste stream of PV materials are predicted to confound the MSW systems (Kan et al., 2008; Lai et al., 2004; Raugei and Fthenakis, 2010).

Previous research has proposed various strategies and infrastructure configurations for EoL PV recovery that mimic other products, for example, extended producer responsibility for nickel-cadmium $(\mathrm{NiCd})$ batteries, centralized second-party collection for CRT monitors, and decentralized processing such as what exists for municipal solid waste(Austin et al., 2005; Eberspacher and Fthenakis, 1997; Fisher et al., 2007; Fthenakis, 2000). Although recycling has been proposed to reduce the lifecycle impact of photovoltaics,(Goe and Gaustad, 2014a; Müller et al., 2006; Smith et al., 2007) there is uncertainty about the environmental impacts of technologies employed and transportation required for recovery. Due to the spatial dispersion of $\mathrm{PV}$ and potential energy intensive thermal recovery process, recovery energy and emissions burdens may outweigh the primary energy savings of recycling. This tradeoff is particularly uncertain for lighter (frameless), low efficiency, low capacity modules i.e. thin-films. In addition, without mandates for collection and given low tipping fees, it is uncertain whether current MSW systems have economic incentive to recover PV at EoL. Another possibility is that since PV installations are a part of buildings, they may be categorized as construction and demolition (C\&D) waste. Most states define C\&D waste as "inert" and "uncontaminated" with a specific list of designated materials like aluminum, steel, cement and glass. C\&D material recovery facilities 
DO NOT DISTRIBUTE. COPY OF MANUSCRIPT UNDER REVIEW.

(MRFs) are typically equipped to recover only bulk metals i.e. Al and steel. They would therefore be unlikely to recover the remainder of EoL PV materials.

The approaches to the location-allocation problem for hazardous and MSW management attempt to answer: where do we locate recycling facilities? How do we decide to send, process, and allocate waste? Previous operations research literature has proposed multi-criteria decision analysis (MCDA) models that solve the location-allocation. These models include multiobjective decision models that optimize economic and environmental criteria(Bah and Tsiko, 2011; Caruso et al., 1993; Chambal et al., 2003; Erkut et al., 2008; Hokkanen and Salminen, 1997; Nema and Gupta, 1999); whereas single objective models consider economic criteria alone(De Feo and De Gisi, 2010; Hu et al., 2002; Karagiannidis and Moussiopoulos, 1998; Sharifi et al., 2009; Şener et al., 2005). Previous work has proposed novel approaches to integrate environmental criteria for example, Caruso et al (1993)(Alves et al., 2009; Caruso et al., 1993)uses scalar weights to optimize both economic, resource waste, and environmental impacts; Nema et al (1999) links facility technology, risk of an accident, and residue generation in a hazardous waste facility setting; and Vaillancourt and Waaub (2002) includes implicitly spatial data e.g. proximity to residential areas to evaluate site environmental impact. Larger models showcase the ability to track internal and external material flows for example, Karagiannidis and Moussiopoulos (1998) (Karagiannidis and Moussiopoulos, 1998; Sumathi et al., 2008) includes four levels of system hierarchy i.e. transfer stations, MRFs, landfills, thermal plants. Other work has integrated key stakeholders in MSW management such as Hokkanen and Salminen (1997) (Bah and Tsiko, 2011; Hokkanen and Salminen, 1997; Kontos et al., 2003) developed a method for optimization irrespective of the number of decision makers and given imprecise data. Several works demonstrate the advantage of dynamic models for policy analysis for example Kirca and Erkip (1988)(Kirca and Erkip, 1988; Siddiqui et al., 1996) interprets a dynamic problem as static using a multi-period model and $\mathrm{Hu}$ et al (2002) (Hu et al., 2002; Sharifi et al., 2009) explores sensitivity to waste treatment requirements. These models lack the nuances of real-life MSW systems in that they do not link facility technology with material recovery rate nor explicitly integrate geographic information in decision-making beyond transport distances. In addition, these models lack an exploration of results sensitivity to assumptions such as the collection rate or waste policy initiatives. These models also neglect to explore tradeoffs of centralized and decentralized MSW infrastructures. 
DO NOT DISTRIBUTE. COPY OF MANUSCRIPT UNDER REVIEW.

Geographic information systems (GIS) literature has proposed several land suitability models to site a hazardous waste facility or landfill (Delgado et al., 2008; Ekmekçioğlu et al., 2010; Gorsevski et al., 2012; Korucu and Karademir, 2013; Hung-Yueh Lin and Kao, 1999; Sharifi et al., 2009; Sumathi et al., 2008).. Collectively, previous GIS-based models demonstrate the important tradeoffs of including qualitative and quantitative criteria for waste facility siting. However, they do not forecast the spatial dispersion of future waste generation nor analyze its impacts on site suitability. Filling this literature gap is important for increasing material recovery spatial aspects and shaping future waste policy .

Several questions arise from the previously mentioned literature gaps: how do we model material recovery for valuable and hazardous wastes with rapid growth and uncertain spatial dispersion? How do we evaluate the influence of spatial (e.g. land use) and non-spatial criteria (e.g. policy) on MSW system configuration? Model parameters such as cost, recovery rate, and land use were explored in the work presented here to quantify the sensitivity of our model to economic, technical, and environmental assumptions.

\subsection{Case Study Area: New York State}

New York State's natural land cover consists primarily of cultivated crops, pasture, woody wetlands, and deciduous forests. The state has a land area of approximately 141 thousand $\mathrm{km} 2$. At least 6,967 separate PV installations are located in the state (Bah and Tsiko, 2011; Gemitzi et al., 2006; National Renewable Energy Laboratory, 2015). The average size of installations is 7.6 $\mathrm{kW}$ and the total state capacity (as of March 2015) is $145 \mathrm{MW}$. There are at least $130 \mathrm{MRFs}$ currently within the state that process a variety of materials such as metals, glass, paper, plastic, and electronics. There are also 37 landfills currently located in the study area. 
DO NOT DISTRIBUTE. COPY OF MANUSCRIPT UNDER REVIEW.

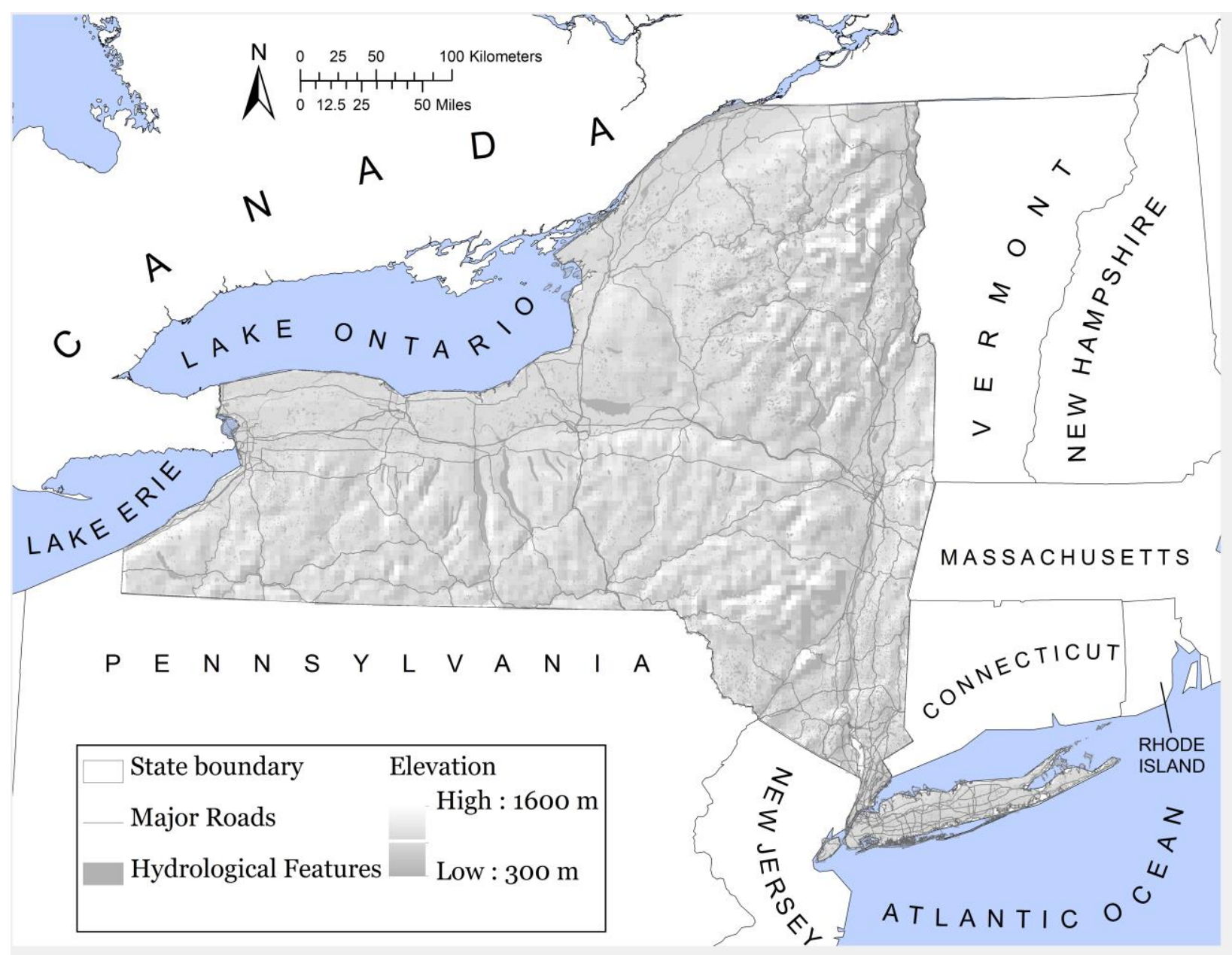

Figure 1. New York State study area including location of major roads, hydrological features, elevation and boundaries.

\section{Proposed Model Formulation}

In order to address current GIS site selection modeling literature gaps, this work integrates spatial statistics with multi-criteria decision analysis (MCDA) tools to quantify three key aspects: spatial dispersion of installed PV (Section 2.1), land suitability for facility location (Section 2.2), and optimal economic allocation of EOL PV to selected locations (Section 2.3) see Supplemental for model schematic.

\subsection{PV Diffusion Model}


DO NOT DISTRIBUTE. COPY OF MANUSCRIPT UNDER REVIEW.

The purpose of the EoL PV diffusion model is to forecast the spatial dispersion and capacity of new PV modules using historical PV installation data. Previous GIS literature assigned PV dispersion based on technical, geographic, and environmental criteria such as land use, rooftop availability, solar insolation, population density and access to grid (Charabi and Gastli, 2011; Y. Choi et al., 2011; Delgado et al., 2008; Demesouka et al., 2013b; Funabashi, 2011; Hofierka and Kaňuk, 2009; Huld and Š́ri, 2003; Kao and Hung-Yue Lin, 1996; Perpiña et al., 2013; Ramirez-Rosado et al., 2011; Tiba et al., 2010; Vardimon, 2011). There are also empirical relationships between PV siting and policy or social criteria. For example, the share of PV capacity is largest among states that have both renewable portfolio standards and economic policy incentives such as subsidies for residents and businesses(Kao and Hung-Yue Lin, 1996; Schelly, 2014; Şener et al., 2005). Recent work has also proposed PV installations are likely to be spatially clustered based on demographics or influences from peers and community organizations(Bah and Tsiko, 2011; Gemitzi et al., 2006; Noll et al., 2014; Rai and McAndrews, 2012; Robinson et al., 2013). If we assume PV capacity is spatially clustered then we would expect new PV installations to be located close to existing installations. For simplicity, we assign new installations to the same location, e.g. XY coordinate or zip code area, as current installations. The size of new installations is set as equal to the average size of current installations at the same location. The total installation capacity at a point represents the neighborhood capacity rather than the likely capacity at the exact XY location. For computing efficiency in larger study areas, we define installation locations by aggregating points within a political boundary e.g. city or zip code. This approach to assigning new PV location and capacity attributes assumes that share of PV capacity is static over the same spatial area.

In order to test our assumption that PV capacity is spatially clustered we calculated the probability that a PV installation will appear in a location near an existing installation using spatial statistics. The null hypothesis states that the spatial relationship between PV installations is random. The use of spatial statistics for this purpose consists of three parts: average nearest neighbor index (ANNI), p-value, and z-score calculations. The average nearest neighbor index has been used to determine clustering of epidemics, diseases (Delgado et al., 2008; Kan et al., 2008; Lai et al., 2004), natural phenomenon(Bishop, 2010; 2007; Guiqin et al., 2009), and population demographic densities (Austin et al., 2005; Çelik et al., 2010; Fisher et al., 2007; Yildiz et al., 2004). It compares the observed mean distance $\bar{D}_{o}$ between each feature and its 
DO NOT DISTRIBUTE. COPY OF MANUSCRIPT UNDER REVIEW.

nearest neighbor with the expected mean distance $\bar{D}_{E}$ for a feature in a random pattern (normal distribution) as shown in Equation 1(Alves et al., 2009; Smith et al., 2007). The expected mean distance $\bar{D}_{E}$ is a function of the total number of features $n$ and the enclosing area $A$ (Equation 3 ). In this case we use set the enclosing area as equal to that within state boundary. The z-score and p-value are two other statistics that determine whether spatial variables are random. The z-score utilizes the difference between the observed and expected mean distance to determine whether clustering is randomized (Equation 2). Random clusters would fall within two standard deviations from the mean of a normal distribution. The p-value determines the probability of obtaining the observed result assuming randomly dispersed features. P-value can be determined from z-score using $\mathrm{z}$ table for a $90 \%$ confidence interval. If any of the geo-statistical variables are statistically significant, then we reject the null hypothesis. We reject the null hypothesis for p-values less than $0.1, \mathrm{z}$ values greater than 0.5 , and ANNI less than 1.

$$
\begin{aligned}
& A N N I=\frac{\bar{D}_{O}}{\bar{D}_{E}} \\
& Z=\frac{\left(\bar{D}_{O}-\bar{D}_{E}\right)}{0.26136} \sqrt{\frac{n^{2}}{A}} \\
& \bar{D}_{E}=0.5 \sqrt{\frac{n}{A}}
\end{aligned}
$$

This approach to PV spatial dispersion is limited in its capacity to forecast location specific adoption over time as well as to account for varying stages of adoption maturity. For example, if we assume the study area is in a mature phase of adoption, then the location of new installations can be predicted with greater certainty. However if spatial areas are in innovative early stage of adoption then, major, novel installations that may spring up where no PV currently exists may not be predicted by this model. It is also possible that clustering groups extend beyond regional or political boundaries are at different stages in product adoption.

\subsection{Site Selection Model}

The purpose of the suitability model is to develop optimal siting for specialized material recovery facilities (MRFs) that process end-of-life solar photovoltaic modules using the 15 map 
DO NOT DISTRIBUTE. COPY OF MANUSCRIPT UNDER REVIEW.

layers shown in Table 1. Boolean, buffering, proximity and average weighted sum overlay methods in ArcGIS Desktop 10.1 were used to determine which sites were suitable for material recovery facility (MRF) siting. Available information related to the technical, environmental, and economic implications of MRF siting was obtained from several publicly available sources detailed in the Supplemental and produced in digital map layers (see Supplemental for schematic). Exclusionary and non-exclusionary criteria were applied to these map layers. Exclusionary criteria include elevation, land use, surface water, coastline, floodplain, fault lines, hospitals and schools. Exclusionary criteria are considered decisive factors that draw a boundary where MRF siting is unsuitable. We eliminate unsuitable sites by utilizing Boolean overlay method similar to previous literature (Bah and Tsiko, 2011; Demesouka et al., 2013a; Gemitzi et al., 2006; Guiqin et al., 2009). Non-exclusionary criteria include proximity to surface water, coastline, major roads, waste production centers, and landfills. Non-exclusionary criteria are subjectively ranked by suitability along a unit-less scale of 1(least favorable) to 10(highly favorable) based on proximity. Moderately suitable values were given a score of 5. Favorability rankings, $\gamma_{u r}$, for each criteria, $v$, and spatial position, $u$, were then linearly combined in an average weighted sum, $S_{i}$, as shown in Equation 4. In this case study, each criteria weight, $w_{v}$, is equal (Equation 5). In practice, experts or stakeholders may weigh criteria by priority, for example using AHP or other subjective outranking methods. The advantage of equally weighted criteria is to reduce the complexity and increase the transparency of the model. The areas deemed suitable were then further filtered out based on assumptions about the maximum socially acceptable facilities per municipality.

$$
\begin{aligned}
& S_{i}=\sum_{r=1} w_{v} y_{v v} \quad \forall u=1,2, \ldots U \\
& w_{v}=\frac{1}{v} \quad \forall v=1,2, \ldots V
\end{aligned}
$$

Table $1 \mathrm{MRF}$ and landfill site selection model criteria description by category

\begin{tabular}{lll}
\hline Category & Map Layer & Criteria Description \\
\hline Land Cover & Elevation & Slope less than 12 degrees \\
& Land cover & Areas with significant economic or ecological value should \\
& & not be considered i.e. wetlands, forest, and cultivated crops \\
Hydrography & Surface water & Sites should be at least $1 \mathrm{~km}$ from rivers, streams, lakes, \\
\hline
\end{tabular}


DO NOT DISTRIBUTE. COPY OF MANUSCRIPT UNDER REVIEW.

\begin{tabular}{|c|c|c|}
\hline & & and ponds \\
\hline & Coastline & $\begin{array}{l}\text { Sites must be at least } 1 \mathrm{~km} \text { from coastline; increase } \\
\text { favorability as proximity to coastline decreases; } 1-5 \mathrm{~km} \text { is } \\
\text { least favorable. } 6-10 \mathrm{~km} \text { is moderately favorable; greater } \\
\text { than } 10 \mathrm{~km} \text { is highly favorable for facility siting }\end{array}$ \\
\hline & Floodplain & Sites must be at least $3 \mathrm{~km}$ from streams \\
\hline Geology & Fault lines & Sites must be at least $0.5 \mathrm{~km}$ from fault lines \\
\hline \multirow[t]{6}{*}{ Infrastructure } & Roads & Sites must be at least $0.2 \mathrm{~km}$ from major roads and schools; \\
\hline & Airports & $1.5 \mathrm{~km}$ from hospitals; $3 \mathrm{~km}$ from airports; increase \\
\hline & Hospitals & suitability as proximity from roads, landfills, and waste \\
\hline & Schools & production centers increase; $0.2-10 \mathrm{~km}$ from is highly \\
\hline & Landfills & favorable; sites between $10-20 \mathrm{~km}$ is moderately \\
\hline & Installations & favorable; more than $20 \mathrm{~km}$ is least favorable \\
\hline Vulnerable & US Census & Sites may not be located within census blocks that contain \\
\hline \multirow[t]{2}{*}{ Populations } & Blocks & greater than $50 \%$ poverty rate or greater than $25 \%$ \\
\hline & & population that is aged over 65 , or under 2 years \\
\hline Site Density & Suitable sites & No more than one site per $50 \mathrm{~km}^{2}$ \\
\hline
\end{tabular}

2.2.1 Land cover. There are 6 major classes of attributes specified in the land cover map layer: forest, barren land, cultivated crops, wetlands, pasture, and shrubs. Previous literature has suggested that landfills and recovery facilities avoid locating in industrial or agricultural areas (Basnet et al., 2001; De Feo and De Gisi, 2010; Sharifi et al., 2009; Şener et al., 2005) while others encourage the use of these areas (Alves et al., 2009; Gemitzi et al., 2006). Landfill leachate that contains arsenic, selenium, or cadmium has the potential to contaminate soil and crops as well as endanger wildlife flora and fauna. Therefore we strictly exclude siting in agricultural areas, wetlands, and forest while allowing siting on barren land, shrubs, and pasture land types. In addition, we increase favorability rating of site as proximity to these areas increases.

2.2.2 Surface water, coastline, floodplain, fault lines and elevation. Previous studies have used a buffer from rivers and streams of 0.1 - $0.5 \mathrm{~km}$ (Demesouka et al., 2013a; Sumathi et al., 
DO NOT DISTRIBUTE. COPY OF MANUSCRIPT UNDER REVIEW.

2008), and 0.5 km (Bah and Tsiko, 2011; Kontos et al., 2003; Perpiña et al., 2013), $0.8 \mathrm{~km}$ (Bah and Tsiko, 2011; Siddiqui et al., 1996; Sumathi et al., 2008), 1 km (Guiqin et al., 2009; Sharifi et al., 2009), and 2-3 km(Aivaliotis, 2004; Kollikkathara et al., 2010; Hung-Yueh Lin and Kao, 1999), We set distance of less than $1 \mathrm{~km}$ from surface water as exclusionary criteria. Unlike inland surface water buffers, coastline boundaries in New York State outline international drinking and fishing water sources of Lake Erie, Lake Ontario, the St. Lawrence River and the Atlantic Ocean. International law discourages "damage" of these waters (Food and Agriculture Organization of the United Nations, 1998; US Environmental Protection Agency, 1991). Previous literature proposes $1 \mathrm{~km}$ (Bah and Tsiko, 2011; Gemitzi et al., 2006) buffer from coastlines. We also set coastline buffer at $1 \mathrm{~km}$ while increasing favorability of siting as proximity to coastline and surface water decreases.

When available we follow (Delgado et al., 2008; Demesouka et al., 2013b; Kao and Hung-Yue Lin, 1996; Perpiña et al., 2013) in setting 0.3 and $0.5 \mathrm{~km}$ distance from floodplains and fault lines as exclusionary, respectively. In regions where data is unavailable, previous work has set 3 km (Kao and Hung-Yue Lin, 1996; Şener et al., 2005) as buffer from rivers and streams.

Previous studies elevation criteria for siting landfills widely vary, buffering at slopes less than 15 degrees (Bah and Tsiko, 2011; Gemitzi et al., 2006), 30 degrees (Delgado et al., 2008), 50 degrees (Guiqin et al., 2009), and between 8-12 degrees (Çelik et al., 2010; Yildiz et al., 2004). We set buffers at elevations between 0-12 degrees with 8-12 degrees being most favorable and 0 degrees being the lease favorable because the above research suggest landfill failures and contamination of water bodies from runoff can be controlled at these angles.

\subsubsection{Waste production centers, landfills, current recovery facilities, roads, and site area.}

In the literature, exclusionary residential area buffers are less than $1 \mathrm{~km}$ (Alves et al., 2009), 0.5 km(Demesouka et al., 2013a; Gemitzi et al., 2006; Guiqin et al., 2009), or 0.25 $\mathrm{km}$ (Basnet et al., 2001). However, the farther away MRF or landfill distance the greater the transport cost, therefore, literature has proposed upper bounds for the proximity to waste production centers of $60 \mathrm{~km}$ (Gemitzi et al., 2006) or $5 \mathrm{~km}$ (Demesouka et al., 2013a), or assigned a transport cost of 47 dollars per ton (Perpiña et al., 2013). We set a proximity from waste production centers (current PV installations) of $2 \mathrm{~km}$ as most favorable and $50 \mathrm{~km}$ as least 
DO NOT DISTRIBUTE. COPY OF MANUSCRIPT UNDER REVIEW.

favorable, while excluding distances less than $0.5 \mathrm{~km}$ from residences and greater than $100 \mathrm{~km}$ from waste production centers.

For better integration into the existing infrastructure and to reduce transport costs, new MRFs should be located near current landfills, transfer stations, roads, and recovery facilities. Previous literature has argued that increasing proximity to roads minimizes cost and facilitates access. However, the flow of large vehicles carrying waste can also potentially hamper transportation in general and therefore exclusionary buffers of $0.2 \mathrm{~km}$ (Bah and Tsiko, 2011; Siddiqui et al., 1996; Sumathi et al., 2008) and $0.1 \mathrm{~km}$ (Guiqin et al., 2009) have been proposed. Given previous literature, we set an exclusionary buffer of $0.2 \mathrm{~km}$ around roads. We also scaled favorability of siting to increase as proximity to roads, current landfills, and recovery facilities increase.

Following the identification of candidate sites, we determine the minimum site area to process the expected waste over the long term (50 years). Previous engineering literature suggests landfill sites require approximately 1 hectare of land for 80,000 metric tons of waste (Aivaliotis, 2004; Kollikkathara et al., 2010). Likewise the site size for a MRF depends on waste capacity. Previous literature suggests MRFs requires between 11,380 and 1,080 square meters for 500 and 10 metric tons per day (TPD), respectively (US Environmental Protection Agency, 1991).

2.2.4 Schools, hospitals, airports, facilities per area, and vulnerable populations. Previous literature also suggest locating sites at a distance of $1.5 \mathrm{~km}$ from sensitive buildings such as hospitals (De Feo and De Gisi, 2010; US Environmental Protection Agency, 2009) 200-800 meters from schools (Charnpratheep et al., 1997; Graedel, 2011; Peiró et al., 2013) and 3 km from airports(Bevc et al., 2007; Demesouka et al., 2013a; Ham et al., 2013). Therefore, we set a buffer of $200 \mathrm{~m}, 3 \mathrm{~km}$, and $1.5 \mathrm{~km}$ from schools, airports, and hospitals, respectively.

Siting should also be sensitive to oppressed and vulnerable populations. Environmental justice literature has recognized that low income populations are more likely to live in proximity to landfills and other sources of toxic releases partially due to political disempowerment (Bevc et al., 2007; Li et al., 2011; Nnorom and Osibanjo, 2008; Osibanjo and Nnorom, 2007; United States Internal Trade Commission, 2013). Health literature has also documented higher rates of disease among the young (below age 2) and elderly (above age 65), especially for those in close proximity to sources of toxic releases (Kouznetsova et al., 2006; Raugei and Fthenakis, 2010; 
DO NOT DISTRIBUTE. COPY OF MANUSCRIPT UNDER REVIEW.

Vrijheid, 2000). In order to take into account the social impacts of siting, we use three population statistics where siting is restricted: greater than 25 percent elderly, greater than 25 percent of young, and a poverty rate above $50 \%$.

Many social science studies have documented the negative attitudes of residents toward locating new landfills and recovery facilities nearby e.g. Not-In-My-Backyard (NIMBY) (Agency for Toxic Substances and Disease Registry, 2007; Goe and Gaustad, 2014a; Kontos et al., 2003; Lober, n.d.; U.S. Geological Survey, 2012). Since some municipalities may have several optimal sites for siting we limit the density of sites considered in any given municipality to less than one per $10 \mathrm{~km}^{2}$ in order to reflect the likely NIMBY attitudes of residents.

\subsection{Location and Technology Allocation Model}

2.3.1 Economic Model. In this section we propose a generic quantitative model for a waste recovery network design. The purpose of this model is to determine the most economically optimal set of landfill and MRF siting alternatives. Our model is based on previous work on municipal solid waste recovery network properties discussed in the introduction that has demonstrated the utility of single-objective multi-period decision models that track internal and external material flows. Building on previous work, this model inputs spatial data from sections $2.1-2.2$, as well as cost and material availability assumptions. The network has three levels customer, facility, and landfill - and materials flow in a forward direction to either the recovery facility or towards the landfill as described in the Supplemental.

The structure presented in the Supplemental Fig. A4 is translated into a mixed integer non-linear program (MINLP) in Equations 6-13. Here we modify the traditional facility location model by including technology decision variables and its recovery rate parameters $\gamma_{k}$ for each facility. In this model there are $I$ customers with end-of-life PV available for collection, $I$ potential material recovery facility (MRF) locations, and $K$ potential recovery technologies. The decision variables are $X_{i j}$, the weight of EoL PV from customer $i$ that is processed at MRF $j ; Y_{i}$, the site location; and $Y_{i k}$, the set of technologies $k$ employed at location $j$. The variable cost parameters of this supply chain include $c_{k}$ technology, $c_{t}$ transportation and $c_{d}$ waste disposal while fixed cost of 
DO NOT DISTRIBUTE. COPY OF MANUSCRIPT UNDER REVIEW.

technology $f_{k}$ and MRF facility $f_{j}$ are also included. The facility capacity parameter is represented by $z_{j}$. The unrecovered portion of demand is represented by $U_{i}$.

$\min \sum_{j \in J} f_{j} Y_{j}+\sum_{j \in J} \sum_{k \in K} f_{k} Y_{j k}+\sum_{j \in J} \sum_{k \in K}\left(\sum_{i \in I} X_{i j}\right) c_{k} Y_{j k}+\sum_{i \in I} \sum_{j \in J} c_{t} t_{i j} X_{i j}+\sum_{i \in I} c_{d} U_{i}$

In this formulation the objective is to minimize the cost of the material recovery network. This objective (equation 6) is subject to constraints of mass balance (equation 7-8), facility \& technology opening conditions (equations 9-11), capacity constraints (equation 12), and nonnegativity (equation 13). This formulation is general and can reflect many different recovery scenarios. For example, we can model mandatory collection by setting the cost of disposal $c_{d}$ to an extremely high or infinite value. We can also simulate a distributed or centralized system by setting $\sum_{j \in J} Y_{j}>1$ or $j=1$ respectively. In addition to a capacity constraint, we can also simulate capacity size decisions. To do this we add the term $\sum_{j \in J} \Sigma_{z \in Z} c_{z} Y_{j z}$ to the general objective function and modify the general capacity constraint (equation 12) as $\sum_{i \in I} X_{i j} Y_{j} \leq \sum_{z \in Z} Y_{j z} z_{j}$. These new terms use a capacity cost parameter $c_{z}$ and facility capacity decision variable $Y_{j z}$. Municipal solid waste networks also vary over time. In order to model network configuration dynamics we can either re-run the model each period with new waste material inputs or define all decision variables within time $t$. A network that is time varying would also require adding to the objective function a penalty $p\left(Y_{j, t}-Y_{j, t-1}\right)$ for closing a facility that was open in the previous period.

$$
\begin{aligned}
& \sum_{j \in J} X_{i j}+U_{i}=d_{i} \quad \forall i \in I \\
& U_{i}=d_{i}-\sum_{j \in J} X_{i j} Y_{j k}+\sum_{j \in J} \sum_{k \in K} X_{i j} Y_{j k}\left(1-\gamma_{k}\right) \quad \forall i \in I \mid \\
& \sum_{i \in I} X_{i j} \leq Y_{j} \quad \forall j \in J \\
& Y_{j k} \leq Y_{j} \quad \forall k \in K \\
& Y_{j k}, Y_{j} \in\{0,1\} \quad \forall j \in J, \forall k \in K
\end{aligned}
$$


DO NOT DISTRIBUTE. COPY OF MANUSCRIPT UNDER REVIEW.

$$
\begin{aligned}
\sum_{i \in I} X_{i j} Y_{j} \leq z_{j} \quad \forall j \in J & \\
X_{i j}, Y_{i j}, Y_{j} & \geq 0 \forall i \in J, \forall j \in J, \forall k \in K
\end{aligned}
$$

The generic model can be widely applied to a variety of geographic locations as well as handle different waste streams beyond PV. It has the following assumptions:

- The network configuration is static i.e. one period model.

- Every specialized MRF can process all materials in a waste stream.

- Landfills will accept all waste materials at a penalty that linearly increases with material weight.

- Every facility must choose among a predetermined set of recovery technologies with a recovery rate of $\gamma_{k}$. The material recovery rate is dependent only on the recovery technology of the facility it is sent to.

- Once materials are put into the waste stream they are immediately processed, therefore, there is no material inventory at a facility; the only storage is at the landfill.

- Once materials arrive at landfill they cannot be recovered; likewise once materials are recovered and sent to secondary materials markets they cannot be disposed of.

- There are no stops along the route from a waste collection point to landfill or MRF. Waste transporters will travel only the shortest route between these stops.

- MRFs, landfills, and secondary markets are co-located, so no additional transport is necessary from MRF to landfill or MRF to secondary market.

- There is no cost to transport waste to landfill from a collection point. The disposal cost linearly increases with the mass of unrecovered waste. The transport cost from waste collection point to MRF varies linearly with distance. This implies that the size and the number of modules does not directly influence transport cost.

For the base case we assume:

- Transportation cost due to diesel fuel of $0.99 \$ / \mathrm{L}$ for a 7.5 ton capacity truck with 3.85 $\mathrm{km} / \mathrm{L}$ fuel economy. 
DO NOT DISTRIBUTE. COPY OF MANUSCRIPT UNDER REVIEW.

- Each facility has 10 metric tons per day (TPD) capacity that requires of $\$ 0.51 \mathrm{M}$ fixed construction cost.

- Available material at each location is proportional to the capacity such that $85 \mathrm{~W}$ capacity module contains approximately $8 \mathrm{~kg}$ of materials.

- There is no cost to transport materials to landfill however there is a disposal cost at the landfill of $\$ 60$ per metric ton.

- The study area will develop a PV capacity of 6,000 MW. All of the PV materials will be available for allocation to MRFs or landfills.

Despite its flexibility there are several aspects of material recovery infrastructure not taken into account with this model. In particular, the temporal uncertainty of EoL modules, which we previously stated is a potentially important aspect of reducing the energy intensity of future photovoltaics, is not modeled explicitly. We address this issue for our case study by analyzing the impact of supply uncertainty on technology and facility location using sensitivity analysis.

2.3.2 Recovery Technology. The degree of recycling and recovery technology used is uncertain despite sparse efforts of module manufacturers such as First Solar and recent European Union (EU) electronics laws mandating recycling for PV modules (Eberspacher and Fthenakis, 1997; European Paraliment and of the Council, 2003; Fthenakis, 2000). There are a variety of processes being developed and currently employed by module manufacturers that vary in cost, methods, and material recovery priority. For example, (Frisson et al., 2000; Goe and Gaustad, 2014a; Müller et al., 2006) describe technology meant to recover silicon modules for remanufacturing. Due to the high manufacturing energy requirements of silicon modules and lack of active secondary market for silicon, this technology has the potential to reap the most primary energy benefits including lowering module energy payback time. Other technologies are aimed at recovering rare expensive module materials such as tellurium despite the high processing costs and uncertain economic benefits (Caruso et al., 1993; Chambal et al., 2003; J. K. Choi and Fthenakis, 2010; Erkut et al., 2008; Hokkanen and Salminen, 1997; Nema and Gupta, 1999). There is also the option of exclusively recovering module glass and frame materials as they reduce the energy payback time by the greatest amount due to being the largest components by weight (Goe and Gaustad, 2014a; Hu et al., 2002; Karagiannidis and 
DO NOT DISTRIBUTE. COPY OF MANUSCRIPT UNDER REVIEW.

Moussiopoulos, 1998). However, depending on available technology and costs, this option may potentially result in landfilling the small amounts of critical and hazardous metals.

In the location allocation model, it is assumed that all MRFs have the option of two recovery paths: (1) limited recycling and (2) exhaustive recycling as shown schematically in3. The "limited" recycling path recovers frame, glass, and laminate materials by manual disassembly, thermal processing, size reduction, leaching, and sieving steps. The "exhaustive" recycling path includes etching, precipitation, and thermal processing in addition to the processes included in the limited route. The technologies employed for each path are module dependent as shown in Table 2. In each recycling path, recovered materials will be sent to scrap markets whereas waste materials will be sent to landfill. In the case of limited recycling, active materials and unrecovered glass are sent to landfill. In the case of exhaustive recycling, dust and unrecovered glass is sent to landfill.

Each module type (i.e. silicon-based or thin-films) also undergoes separate processing steps summarized in Table 2 and the Supplemental. Silicon-based modules first are manually dissembled of frame materials, then undergo thermal and chemical processing before being crushed in order to recover frame, silicon, and glass materials following the Deutsche Solar process described in literature (Bohland and Anisimov, 2000; Caruso et al., 1993; Wang et al., 2012; Yamashita et al., 2006). These processes have yielded up to $90 \%$ and $95 \%$ recovery of silicon and glass, respectively. Thin-films copper-indium-gallium-diselenide (CIGS) and cadmium telluride (CdTe) modules first will be shredded, spun, and then undergo leaching and precipitation in order to separate out ethyl vinyl acetate (EVA) and organics while recovering glass and active materials following the First Solar process described in literature (Berger et al., 2010; Bohland et al., 1997; J. K. Choi and Fthenakis, 2010; Goozner et al., 1999; Karagiannidis and Moussiopoulos, 1998; Marwede et al., 2013). This process has reported yields between 90 95\% Cd, Te and 99\% glass from CdTe modules. A similar process that additionally incorporates electrolysis after sieving yields 94\% $\mathrm{Cu}$ and $88-90 \%$ Se from CIGS modules(Dinkard et al., 1998; Hokkanen and Salminen, 1997). The above literature suggests the same results can be obtained by replacing the energy intensive electro-winning step with multiple precipitation cycles. There are few literature sources exploring amorphous silicon (a-Si) recycling methods and costs, therefore, we assume this module type will be recycled using the same steps as other silicon-based modules. 
DO NOT DISTRIBUTE. COPY OF MANUSCRIPT UNDER REVIEW.

Each recovery process and path has variable costs, fixed equipment costs, and process efficiency assumptions based on data from literature (Table 4). Processing cost for thin-films (T1 - T4 in Table 5) based on Choi and Fthenakis (2010) include utilities, waste treatment, overhead, maintenance, tools, and consumables. Processing cost for silicon-based modules (S1 - S2), based on a bench scale process described by Frisson et al (2000), include utilities, consumables, waste treatment, and labor. We assume a large commercial recovery facility will be able to improve costs over bench scale by $70 \%$ based on energy technology learning research (Kirca and Erkip, 1988; Kobos et al., 2006). In addition to the process specific equipment, we assume a forklift and conveyor belts are required for transporting materials throughout the plant. Conveyor belts are assumed to be used to feed into size reduction and spinning processes as described in literature(Bohland et al., 1997; Hu et al., 2002). We estimate the equipment cost is $\$ 1,500$ and $\$ 9,000$ for a conveyor system and forklift based on data from equipment manufacturers(Delgado et al., 2008; Ekmekçioğlu et al., 2010; Gorsevski et al., 2012; Korucu and Karademir, 2013; Sharifi et al., 2009; Sumathi et al., 2008; Toyota Industrial Equipment, 2014; W.W. Grainger Inc, 2014). The variable cost is $\$ 2.5$ per ton for the forklift based on Choi and Fthenakis (2010). For processing step S0, we assume PV module frames can be disassembled in 3 minutes for a labor wage of $\$ 9$ per hour. Overhead costs are 1.5 times total labor cost.

Table 2 Thin-film module recovery description, fixed equipment and process costs by name

\begin{tabular}{|c|c|c|c|c|c|}
\hline ID & $\begin{array}{l}\text { Process } \\
\text { Name }\end{array}$ & Description & $\begin{array}{c}\text { Processing } \\
\qquad(\$ / \mathrm{mt})\end{array}$ & $\begin{array}{c}\text { Equipment } \\
\text { Name }\end{array}$ & $\begin{array}{c}\text { Equipment } \\
(\$ 100)\end{array}$ \\
\hline \multirow[t]{2}{*}{$\mathrm{T} 1$} & Size & separate glass from laminate & 22.2 & Shredder & 100 \\
\hline & Reduction & & & Hammermill & 100 \\
\hline \multirow[t]{4}{*}{$\mathrm{T} 2$} & Spin & semiconductor film removal & 58.9 & Rotating & 20 \\
\hline & & from glass substrate using & & drum & 10 \\
\hline & & slowly rotating drum with & & Classifier & \\
\hline & & acids & & & \\
\hline \multirow[t]{2}{*}{$\mathrm{T} 3$} & Leaching & solid/liquid separation, glass & 18.2 & Screen & 50 \\
\hline & & rinse & & 100 L Tank & 5 \\
\hline \multirow[t]{2}{*}{$\mathrm{T} 4$} & Precipitation & precipitation of precious & 22.5 & 100 L Tank & 5 \\
\hline & & metals & & & \\
\hline
\end{tabular}


DO NOT DISTRIBUTE. COPY OF MANUSCRIPT UNDER REVIEW.

\begin{tabular}{lllllc}
\hline S0 & Disassembly & detach frame, junction box, & 36 & Hand tools & 3 \\
& & & & \\
and cables with hand tools & & & \\
S1 & Thermal & glass/laminate separation, & 138 & Furnace & 50 \\
& & neutralize furnace emissions & & After burner & 300 \\
S2 Etching & remove Ag material from & 209 & 100 L Tank & 5 \\
& & & & \\
\hline
\end{tabular}

\section{Results}

\subsection{PV Diffusion and Site Selection}

The method used to spatially allocate future waste sources has significant impact on land suitability and infrastructure decisions. For example, allocating future waste to locations of previous waste sites (current PV installations) increases the favorability of MRF siting near current landfills. This is likely due to prevalence of previous waste sites in highly populated areas where waste management has developed supporting infrastructure i.e. landfills and transfer stations accessible by major roads that lead to highly populated neighborhoods. Another allocation scheme is to randomly assign locations within the study area. The spatial statistics indicate that the former method of allocation using previous waste sites is consistent with the spatial relationships of PV installations. That is, for the locations of current PV installations in the study area, there is less than $1 \%$ likelihood that the clustering pattern is a result of random chance for all categories of installations as shown in the Supplemental. This method is valuable to waste planning organizations looking to include waste production centers as a part of land suitability especially when waste dispersion is uncertain. When siting a material recovery center or landfill the location of waste sources directly impacts waste costs e.g. transportation, export/import fees and inventory. This is especially true for valuable or toxic wastes, which require physical separation from municipal flows. If the location of new waste sources over a large geographical area is uncertain, then analysis of current waste source clustering provides more statistical certainty than a random allocation scheme.

After applying both exclusionary and non-exclusionary land suitability criteria we have determined that there are at least 9 sites that are highly suitable for MRF siting (labeled F1-F9 in 
DO NOT DISTRIBUTE. COPY OF MANUSCRIPT UNDER REVIEW.

Figure 2). Many alternative highly suitable sites were eliminated because they were too dispersed or did not meet the area size criteria. The final 9 sites are all within $14 \mathrm{~km}$ of a current landfill, and $9 \mathrm{~km}$ of a current PV installation as shown in Supplemental. There is no more than 1 site per county. The majority $(80 \%)$ of counties do not contain a site although they all contain at least one current PV installation. Of the final 9 sites, F3 has the least combined distance to residential (less than 10kW) and large capacity installations (over $75 \mathrm{~kW}$ ). F4 and F5 are the nearest to hydrographical features i.e. rivers, streams, lakes, coastline.

The land suitability analysis determined that the majority of the study area is either unsuitable or poorly suitable for the siting of an MRF as shown in Table 3. Non-exclusionary criteria reduced the suitable areas by $86 \%$. This is largely due to environmental criteria: land cover and hydrography. For example, surface water and cultivated crops accounted for 54\% and 33\%, respectively, of study area unsuitability. The high density of roads in the densely populated urban areas also resulted in $15 \%$ of study area unsuitability. There is a great deal of overlap between exclusionary features due to the size of the buffer criteria and close spatial relationships e.g. roads and schools. The observed criteria redundancy also suggests that reducing exclusionary criteria to fewer, more meaningful categories may achieve similar results. For our study area, reducing exclusionary criteria from 11 to 3 features (roads, cultivated crops, and surface water) achieves $90 \%$ of the original suitability area.

Table 3. Suitability ranking by total and percent of study area for base case

\begin{tabular}{lcc}
\hline Suitability Ranking & Area $(\mathrm{km} 2)$ & Percent Area \\
\hline Highly Favorable & 5,031 & $4 \%$ \\
Moderately Favorable & 11,320 & $9 \%$ \\
Poorly Favorable & 1,258 & $1 \%$ \\
Unsuitable & 107,766 & $86 \%$ \\
\hline
\end{tabular}


DO NOT DISTRIBUTE. COPY OF MANUSCRIPT UNDER REVIEW.

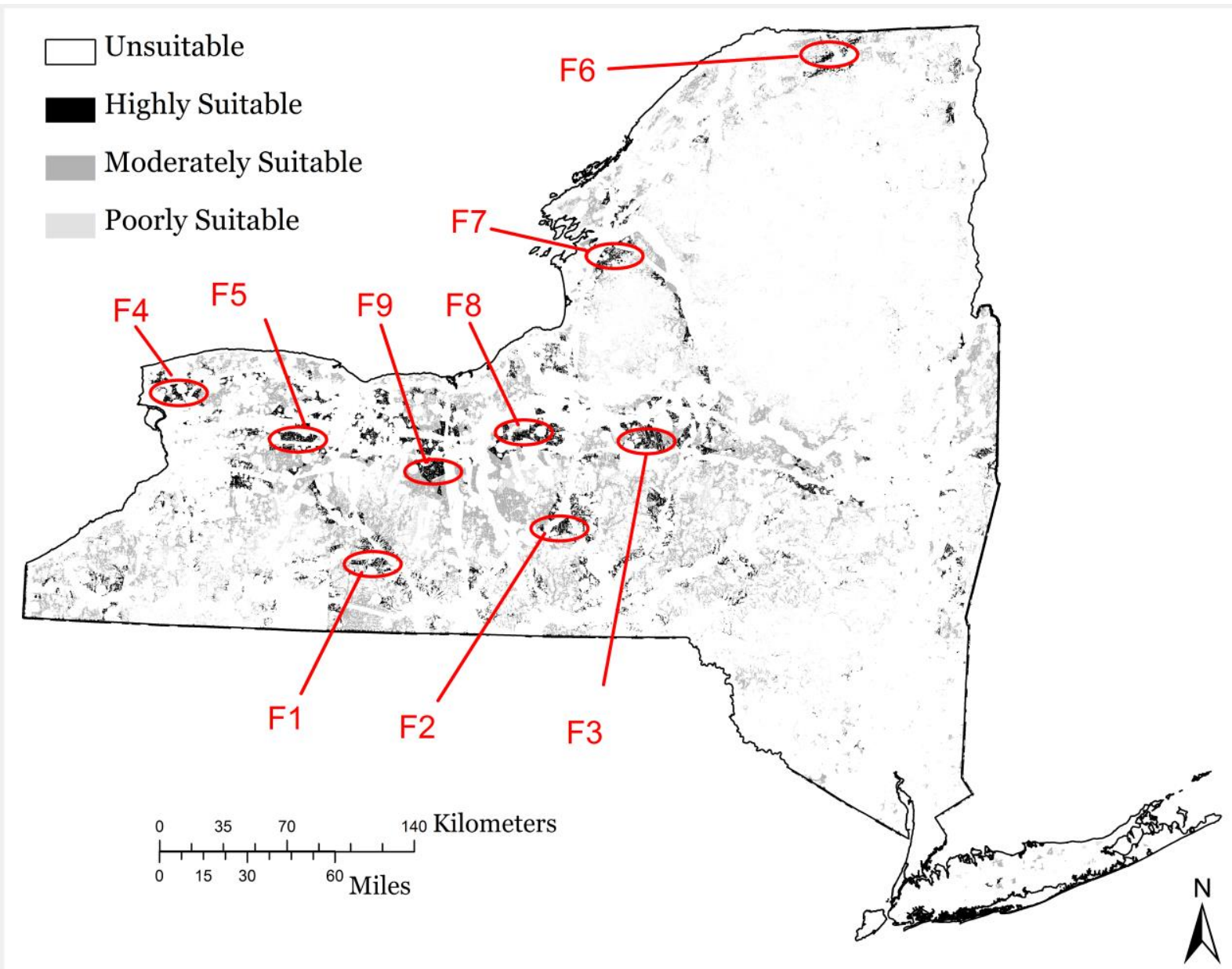

Figure 2 Map of suitable sites (F1-F9) and suitability rankings: unsuitable (white), poorly favorable (light grey), moderately suitable (dark grey), and highly suitable (black)

The choice and weighting of criteria have broad implications for the perceived suitability of sites. The author's land suitability method implies a higher priority for social and environmental considerations because $80 \%$ of the criteria pertain to either environmental or social features. Changing the priority of economic, social, and environmental criteria may be desirable from various stakeholders' perspectives due its ability to produce desired land suitability results; also called geodesign. For example, from the perspective of MRF plant manager, high priority for economic criteria may be desirable in order to reduce transport costs. Increasing the weight of economic criteria in the overlay analysis increases the availability of sites near urban centers, landfills, and roads as shown in Figure 3A. In contrast, an ecologist or environmental group may desire to increase priority for hydrology, wetlands, and forests for greater conservation of 
DO NOT DISTRIBUTE. COPY OF MANUSCRIPT UNDER REVIEW.

habitats and species. Increasing the weight of environmental criteria decreases availability of sites near open water, wetlands, and crops as shown in Figure 3B. When comparing the two approaches, it is interesting to note that a higher priority for environmental criteria increases the number of highly suitable areas. This occurs because environmental criteria are binary (except coastline) whereas economic criteria are continuous. That is for environmental criteria, a site is highly suitable as long as it does not overlap physical features such as floodplains, rivers, and surface water. Since the majority of the study area is developed, there are fewer areas in conflict with preferences of the ecologist, as opposed to the MRF plant manager. These examples demonstrate that the participating stakeholders and experts can heavily influence siting decisions. Gathering the widest possible consensus of interests may increase the likelihood that siting decisions are not dominated by a single interest or criteria.

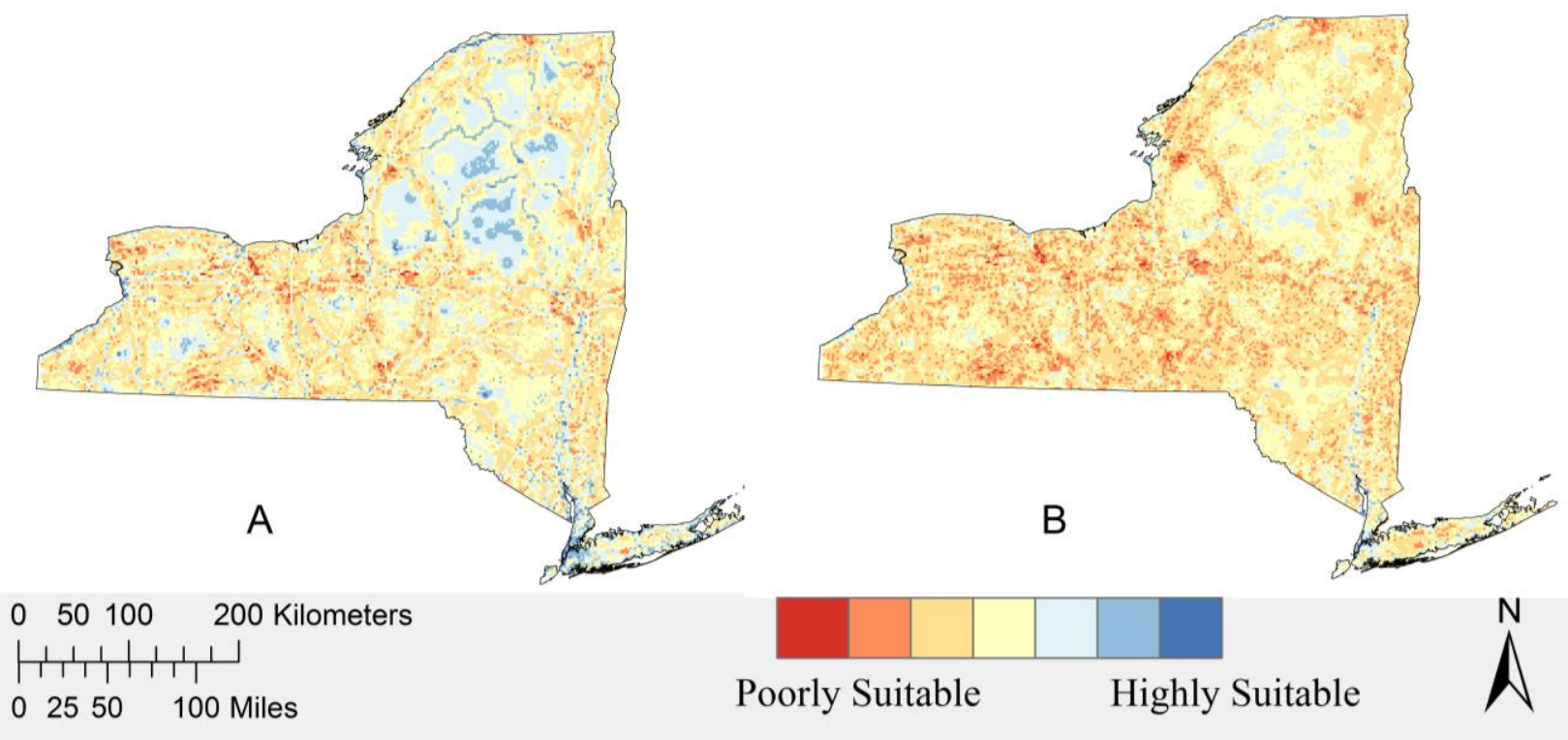

Figure 3 (A) Increasing the economic priority for siting produces high suitability of sites near urban centers, landfills, and roads. (B)

\subsection{Location - Technology Allocation Model Results and Waste Policy Analysis}

The allocation of materials for recovery depends on the fixed and variable costs of disposal, technology, construction, and transportation. For the base case, the lowest cost solution ( $\$ 0.5 \mathrm{M})$ is to allocate all materials to landfill. This means all $X_{i j}$ and $Y_{i}$ are zero as shown in Table 4. 
DO NOT DISTRIBUTE. COPY OF MANUSCRIPT UNDER REVIEW.

Adding a constraint to the base case such as mandatory collection increases the number of selected sites. For example, in Table 8 and Figure 5B when 25\% collection is mandatory, then two sites, F4 and F3 are selected for limited material recovery. When mandatory collection is further increased to $75 \%$ then F1, F2, F3, F4, F6, F7 are selected for limited material recovery, respectively. Although, mandatory collection increases the number of sites selected it also increases the unutilized capacity of each site. This reflects the tradeoff between transportation costs and fixed construction and technology costs.

Decreasing the MRF construction or technology costs, individually, does not change the number of selected sites from the base case. It is only when either the disposal cost is increased or the transport cost is decreased that the model allocates materials to newly sited MRFs. Decreased transport cost implies lower fuel cost and greater vehicle fuel economy, which may require smaller trucks and more trips. An increased disposal cost implies increased landfill tip fee, which is set by municipal waste managers. As the tip fee is increased, the collection rate and total system cost increases as shown in Figure 5. This result indicates that tip fee may be utilized as a policy mechanism to incentivize material recovery. However, this requires coordination to avoid the negative environmental impacts of greater waste transport. For example, waste haulers conscious of high tip fees in one municipality, may decide to transport waste further to a cheaper landfill, thereby increasing transport costs on a system level. From our case study, statewide disposal costs would need to increase to $\$ 1350$ and $\$ 2000$ per metric ton in order to achieve 50\% and $98 \%$ collection rate for recycling, respectively. This would require a substantial cost increase of current landfill tip fees in the study area, which range from $\$ 50$ to $\$ 120$ per ton for C\&D, WEEE, and MSW.

There are multiple tradeoffs between variable costs, fixed costs, and recovery rate. The recovery rate is directly influenced by technology and material allocation model decisions. For the base case, with tip fees above $\$ 1300$, a limited recycling technology path is optimal. A limited recycling path recovers $95-99 \%$ by mass or between $\$ 20-350$ per metric ton-module depending on whether the module is framed or unframed. However, limited recycling leaves materials that are small but critical and valuable parts of the overall mass. For example, the primary value of crystalline silicon (c-Si) technologies is $\$ 450$. Silicon, which would only be recovered on the exhaustive path, makes up $28 \%$ of this value and $4.5 \%$ of module mass. Thinfilm technologies - CdTe, CIGS, a-Si are worth $\$ 60, \$ 550$, and $\$ 700$ per ton-module, 
DO NOT DISTRIBUTE. COPY OF MANUSCRIPT UNDER REVIEW.

respectively. For thin-films, critical materials are between $4-60 \%$ of the module value and less than $1 \%$ of module mass. The criticality of a material is determined by global forces such as the geopolitical instability of primary producers, geological availability, and the economic importance of domestic industries that utilize it. For silicon and thin-film technologies, active materials that exist in small (less than 5\% mass) compositions i.e. Te, Ga, $\mathrm{Si}, \mathrm{In}$, and Te have been ranked high in terms of criticality risk(Demesouka et al., 2013a; Goe and Gaustad, 2014b; Nassar et al., 2012). Recycling is important for critical materials because it provides a domestic a supply chain that may potentially decrease future material scarcity.

Constraining the model to meet a minimum collection rate increases material allocation to MRFs as shown in Figure 6. As the collection rate increases from 0 to $40 \%$, total, fixed, technology, and transport costs per ton decrease. The lowest system cost is achieved at $40 \%$ collection rate. After $40 \%$, the total, fixed, and transport costs per ton increase. As more materials are allocated to MRFs, capacity is reached and more MRFs are required to open, which increases the fixed cost of the system. Likewise, the first materials allocated are those closest (less than $50 \mathrm{~km}$ ) to the active MRFs, which are the small (less than $5 \mathrm{~kW}$ ) residential installations. For the study area, the large (greater than $500 \mathrm{~kW}$ ) commercial installations are clustered between 50-250 $\mathrm{km}$ from the nearest MRF, therefore, as the collection rate increases above $40 \%$, the transport costs increase. In reality, large concentrated commercial installations are more likely to be the target of waste policy rather than dispersed residential installations. Therefore, siting and waste policy should take into account the likely source of materials given collection rate targets.

Despite the use of a minimum collection rate, the limited recycling technology path is always optimal. An exhaustive recycling technology path is optimal only when it is less than the difference between limited recycling technology and the disposal costs. For example, in the case where 10 metric tons of materials are collected to one facility, the limited recycling technology path incurs equipment, processing, and labor costs totaling $\$ 76,160$ in addition to disposal cost for unrecovered (critical) materials (at $\$ 60$ per metric at $80 \%$ recovery rate) of $\$ 120$. In order to encourage the model to choose exhaustive recovery the cost of equipment, processing and labor should be $\$ 11,000$ cheaper than the current cost or $\$ 76,262$, the difference of the limited technology path and exhaustive disposal cost (at 97\% recovery rate). For a facility that processes 10 metric tons per day, the cost savings can add to millions over a couple of years. As the tip fee 
DO NOT DISTRIBUTE. COPY OF MANUSCRIPT UNDER REVIEW.

and collection rate increases, technology costs will have to be further discounted to encourage exhaustive recovery. This case exposes the problem of the lack of coordination between waste policies. The use of a single-action waste policy like tipping fees is insufficient to drive exhaustive material recovery. In order to achieve exhaustive recovery, waste policies should be coordinated with optimal tip fees, collection rate targets, and subsidies for recovery technology.

Table 4 Location and technology allocation MINLP results

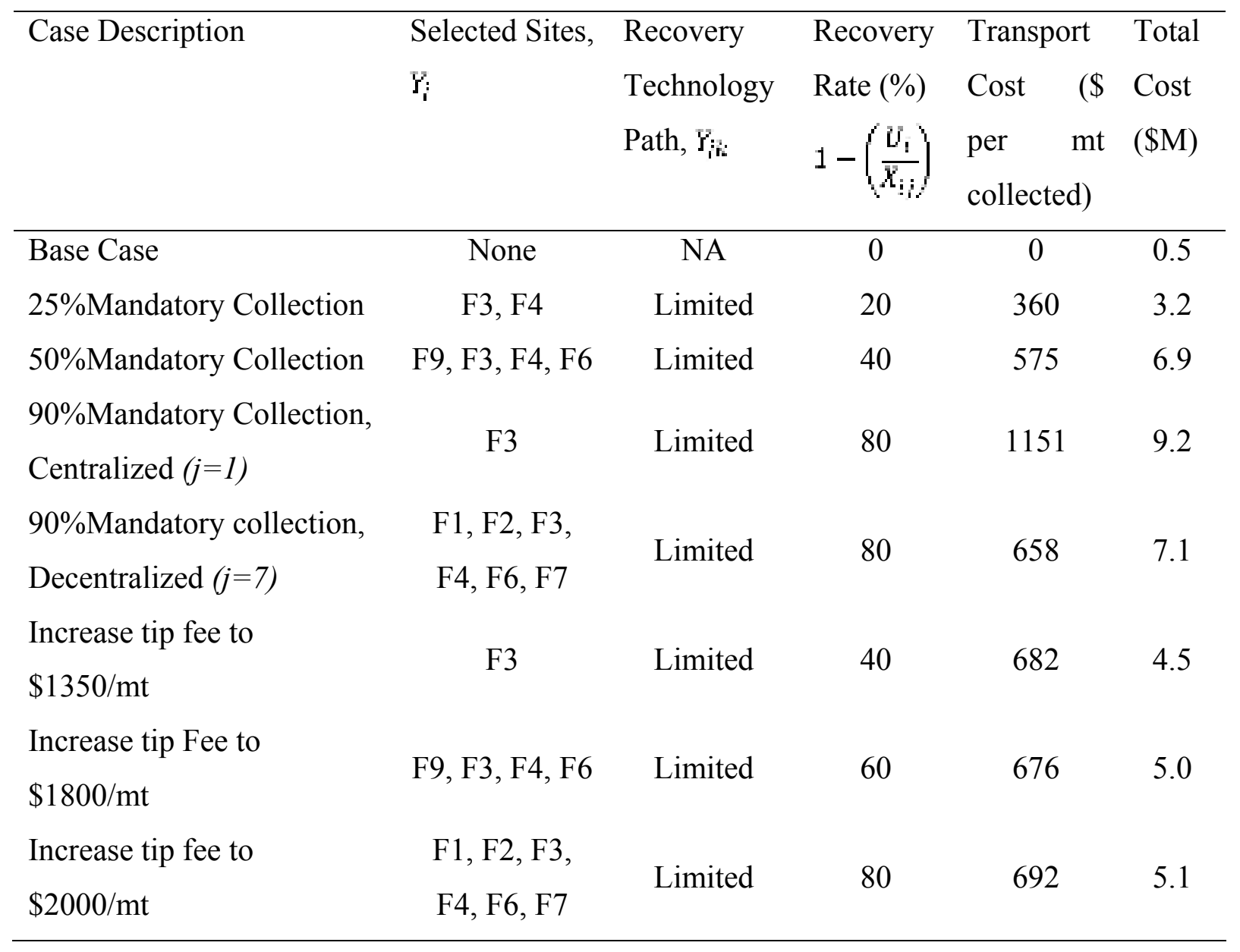




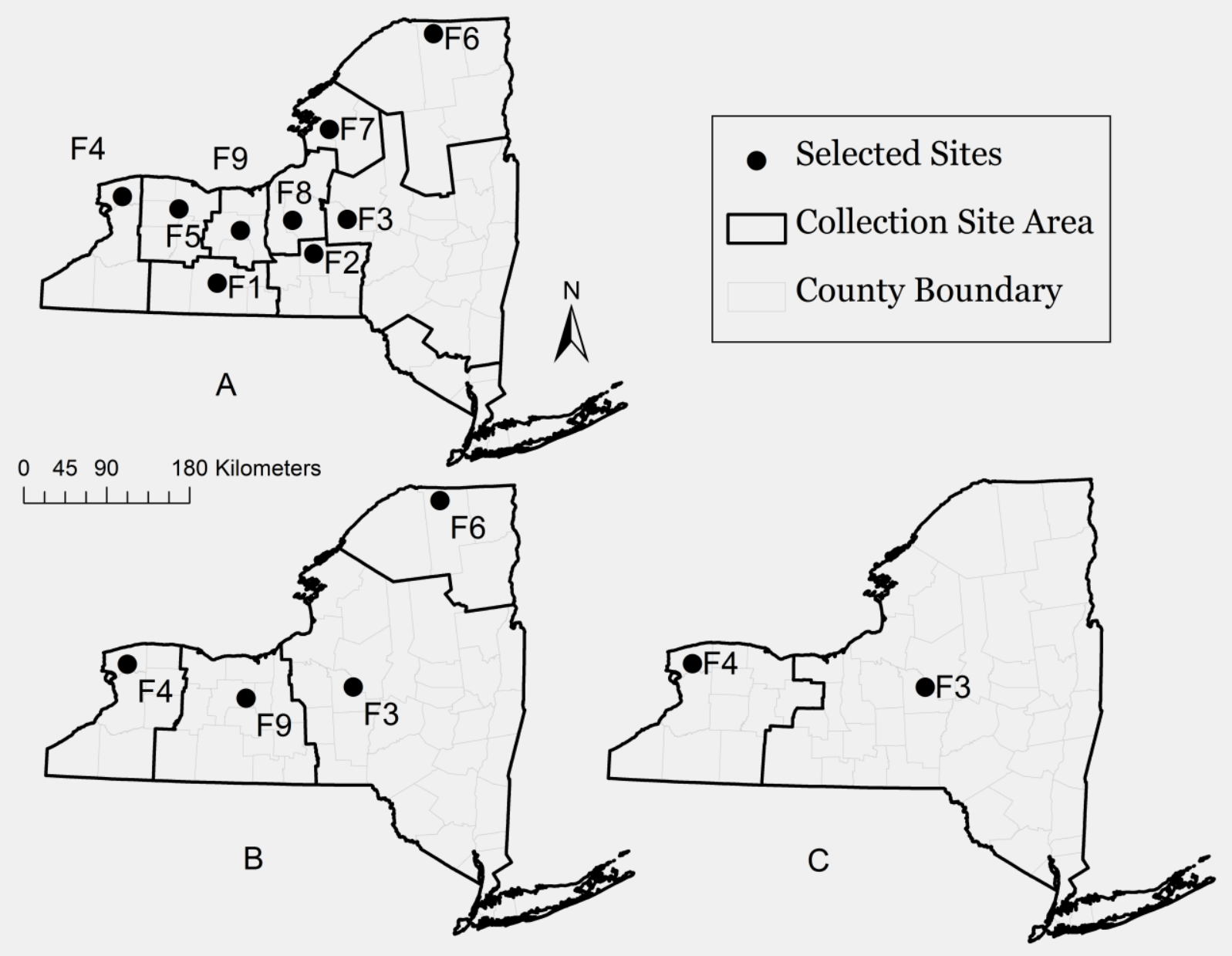

Figure 4 Selected sites and collection area for (A) decentralized and 100\% mandatory collection, (B) $50 \%$ mandatory collection and (C) $25 \%$ mandatory collection. 
DO NOT DISTRIBUTE. COPY OF MANUSCRIPT UNDER REVIEW.

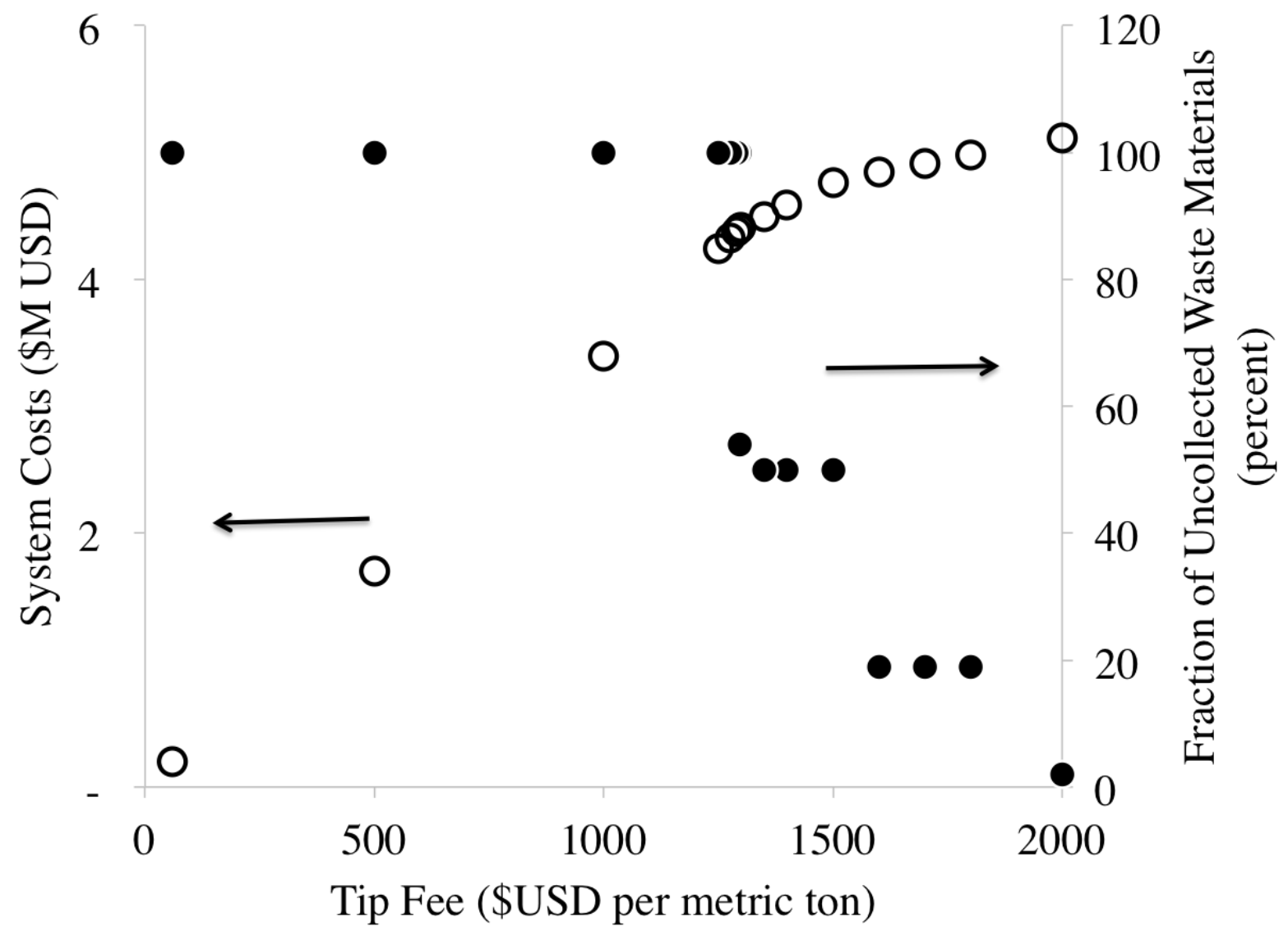

Figure 5 Total cost (open points) and percent uncollected waste materials (closed points) as a function of tip fee for the base case 


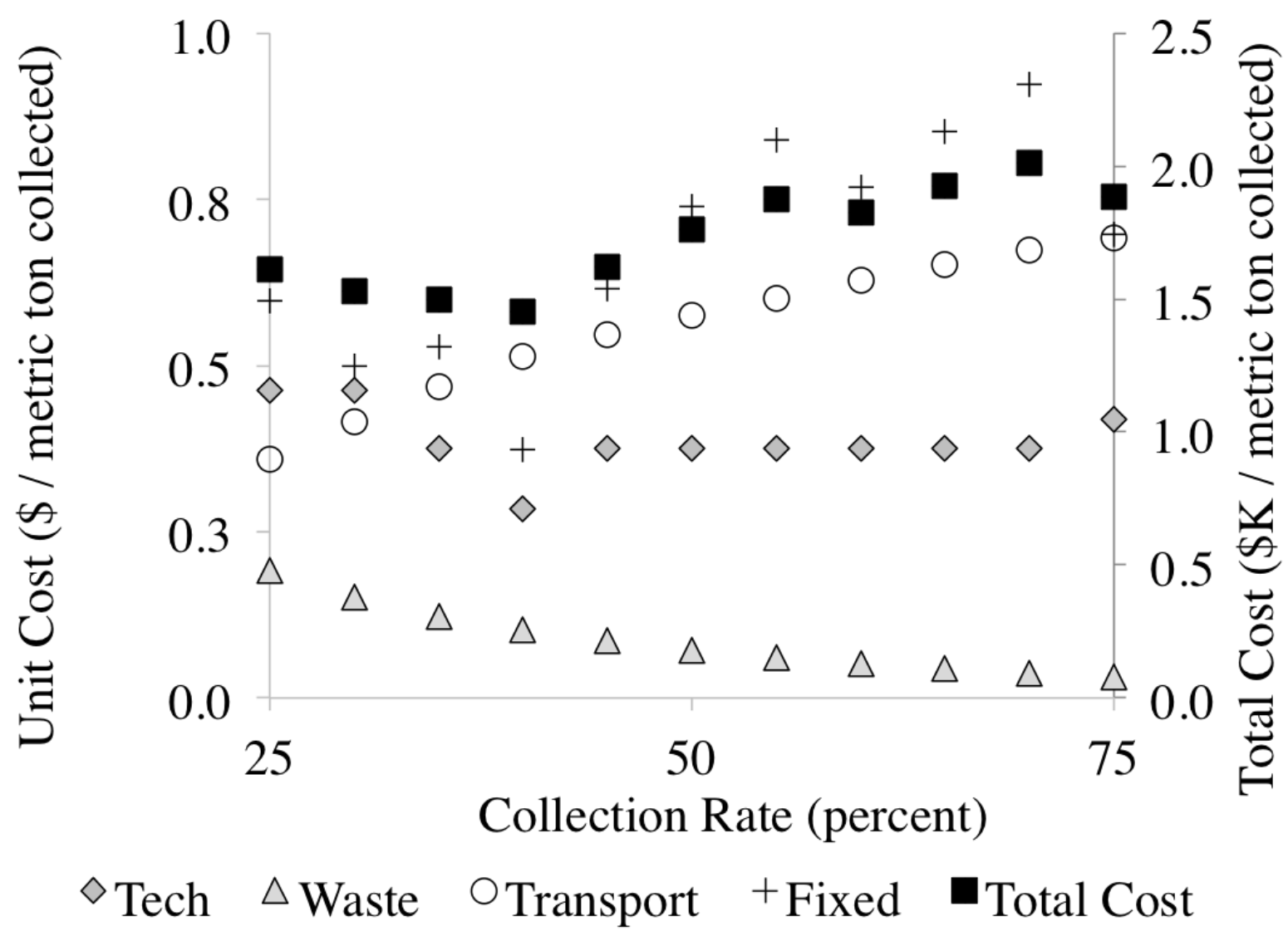

Figure 6 The per unit transportation, disposal, fixed, and technology, cost for a given collection rate.

\section{Conclusions}

In this paper we have explored the social, economic, and environmental tradeoffs of siting a material recovery infrastructure for photovoltaics. We developed a model that combines multicriteria decision analysis with GIS tools, a novel approach that can be applied to a variety of geographic locations and differing waste streams. The model is applied to a case study for the state of New York, a location with aggressive renewable energy goals despite mediocre adaption rates. For example, in terms of current PV installed capacity per capita New York State is similar to Taiwan and China, who each require 40 times higher adaption to equal Germany, the world leader.

For the case study, the results indicate that current PV locations, particularly small capacity installations (i.e. less than $10 \mathrm{kw}$ ), are spatially clustered, a likely finding for non-New York State cases as well. This result illustrates the importance of gathering spatial data for infrastructure 
DO NOT DISTRIBUTE. COPY OF MANUSCRIPT UNDER REVIEW.

decisions where proximity to waste source is an important aspect of per unit costs e.g. transportation, export/import fees and inventory. An extension of this analysis would be to use other relevant criteria e.g. population density to predict future adoption in order to compare final site selection results. This case study is representative for many other states in the U.S. as well as international locations that have low to moderate incentives for PV adoption and relatively long economic payback times (i.e. 5 - 10 years) due to a combination of electricity price and limited solar irradiance.

Utilizing spatial analysis with equally weighted criteria resulted in 9 'highly' suitable alternatives for landfill/MRF siting all of which coincided with (i.e. within 0-14 km of) a current waste facility. These 'highly' suitable alternatives were produced from a combination of a Boolean overlay of exclusionary criteria e.g. hydrological features, roads, elevation and an average weighted sum of non-exclusionary criteria scores e.g. proximity to wetlands, urban centers.. After applying exclusionary criteria to the study area, $86 \%$ was deemed unsuitable for siting while less than $5 \%$ is characterized as highly suitable. This method implicitly prioritized social and environmental concerns over economics and therefore, these concerns accounted for the majority of siting decisions. As we increased the priority of economic criteria, the likelihood of siting near ecologically sensitive areas such as coastline or socially vulnerable areas such as urban centers increased. These examples demonstrate that the participating stakeholders and experts can heavily influence siting decisions. Gathering the widest possible consensus of interests may increase the likelihood that siting decisions are not dominated by a single interest or criteria. Accounting for the direct environmental impacts of technology and siting decisions for recycling solar photovoltaics has not been done and therefore is currently under investigation by the authors.

In order to determine which of the alternative sites produced the least total system cost the authors developed a mixed integer non-linear program (MINLP) that modifies the classic location-allocation problem by adding a technology decision. The results of the MINLP suggest that coordinated policy action is required to encourage the recycling of photovoltaic materials since the cost of disposal is lower than the cost of material recovery. In particular, our model estimates, for the base case, a tip fee of $\$ 2000$ per ton would achieve nearly $100 \%$ collection rate. However, collection rate alone does not efficiently encourage exhaustive recycling. The model results show that exhaustive recovery requires a multi-pronged approach that lowers 
DO NOT DISTRIBUTE. COPY OF MANUSCRIPT UNDER REVIEW.

technology costs, imposes a minimum collection rate, and implements higher tip fees. This result is relevant for all geographic locations with weak recycling policy for emerging waste types with complex compositions, expensive recovery paths, and wide spatial dispersion. Future work in this area may also include evaluating economic and environmental impacts of exporting photovoltaic waste for recovery overseas.

\section{Acknowledgements}

The research team would like to acknowledge funding from the Golisano Institute for Sustainability, the National Science Foundation Environmental Health and Safety of Nanomaterials directorate under Award No. CBET-1133425, and the National Science Foundation Environmental Sustainability directorate under Award No. CBET-1133422.

\section{References}

Agency for Toxic Substances and Disease Registry, 2007. CERCLA Priority List of Hazardous Substances. US Department of Health and Human Services Agency for Toxic Substances and Disease Registry.

Aivaliotis, V., 2004. Functional Relationships of Landfill and Landraise Capacity with Design and Operation Parameters. Waste Manage. Res. 22, 283-290.

Alves, M.C.M., Beatriz S. L. P. Lima, Evsukoff, A.G., Vieira, I.N., 2009. Developing a fuzzy decision support system to determine the location of a landfill site. Waste Manage. Res. 27, 641-651.

Austin, S.B., Melly, S.J., Sanchez, B.N., Patel, A., Buka, S., Gortmaker, S.L., 2005. Clustering of fast-food restaurants around schools: a novel application of spatial statistics to the study of food environments. Am. J. Public Health 95, 1575.

Bah, Y., Tsiko, R.G., 2011. Landfill Site Selection by Integrating Geographical Information Systems and Multi-Criteria Decision Analysis: A Case Study of Freetown, Sierra Leone. Afr. Geogr. Rev. 30, 67-99.

Basnet, B.B., Apan, A.A., Raine, S.R., 2001. Selecting Suitable Sites for Animal Waste Application Using a Raster GIS. Environ. Manage. 28, 519-531.

Berger, W., Simon, F.-G., Weimann, K., Alsema, E.A., 2010. A novel approach for the recycling of thin film photovoltaic modules. Resour., Conserv., and Recy. 54, 711-718.

Bevc, C.A., Marshall, B.K., Picou, J.S., 2007. Environmental justice and toxic exposure: Toward 
DO NOT DISTRIBUTE. COPY OF MANUSCRIPT UNDER REVIEW.

a spatial model of physical health and psychological well-being. Social Sci. Res. 36, 48-67.

Bishop, M.A., 2007. Point pattern analysis of north polar crescentic dunes, Mars: A geography of dune self-organization. Icarus 191, 151-157.

Bishop, M.A., 2010. Nearest neighbor analysis of mega-barchanoid dunes, Ar Rub' al Khali, sand sea: The application of geographical indicies to the understanding of dune field selforganization, maturity, and environmental change. Geomorphology 120, 186-194.

Bohland, J., Anisimov, I., Dapkus, T., 1997. Economic recycling of CdTe photovoltaic modules, in:. Presented at the Conference Record of the Twenty-Sixth IEEE Photovoltaic Specialists Conf., Anahiem, pp. 355-358.

Bohland, J., Anisimov, I.I., 2000. Recycling Silicon Photovoltaic Modules. US Patent 6,063,996. Washington, D.C.: U.S.

Caruso, C., Colorni, A., Paruccini, M., 1993. The regional urban solid waste management system: a modelling approach. Eur. J. Oper. Res. 70, 16-30.

Chambal, S., Shoviak, M., Thal, A.E., 2003. Decision analysis methodology to evaluate integrated solid waste management alternatives. Environ. Model Assess. 8, 25-34.

Charabi, Y., Gastli, A., 2011. PV site suitability analysis using GIS-based spatial fuzzy multicriteria evaluation. Renew. Energ. 36, 2554-2561.

Charnpratheep, K., Zhou, Q., Garner, B., 1997. Preliminary landfill site screening using fuzzy geographical information systems. Waste Manage. Res. 15, 197-215.

Choi, J.K., Fthenakis, V.M., 2010. Economic Feasibility of Recycling Photovoltaic Modules. J. Ind. Ecol. 14, 947-964. .:10.1111/j.1530-9290.2010.00289.x

Choi, Y., Rayl, J., Tammineedi, C., Brownson, J.R.S., 2011. PV Analyst: Coupling ArcGIS with TRNSYS to assess distributed photovoltaic potential in urban areas. Solar Energy 85, 29242939.

Çelik, B., Girgin, S., Yazıc1, A., Ünlü, K., 2010. A decision support system for assessing landfill performance. Waste Manage. 30, 72-81. doi:10.1016/j.wasman.2009.09.016

De Feo, G., De Gisi, S., 2010. Using an innovative critieria weighting tool for stakeholders involvement to rank MSW facility sites with AHP. Waste Manage. 30, 2370-2382.

Delgado, O.B., Mendoza, M., Granados, E.L., Geneletti, D., 2008. Analysis of land suitability for the siting of inter-municipal landfills in the Cuitzeo Lake Basin, Mexico. Waste Manage. $28,1137-1146$. 
DO NOT DISTRIBUTE. COPY OF MANUSCRIPT UNDER REVIEW.

Demesouka, O.E., Vavatsikos, A.P., Anagnostopoulos, K.P., 2013a. Suitability analysis for siting MSW landfills and its multicriteria spatial decision support system: Method, implementation and case study. Waste Manage. 33, 1190-1206.

Demesouka, O.E., Vavatsikos, A.P., Anagnostopoulos, K.P., 2013b. Spatial UTA (S-UTA) - A new approach for raster-based GIS multicriteria suitability analysis and its use in implementing natural systems for wastewater treatment. Journal of Environ. Manag. 125, 41-54. doi:10.1016/j.jenvman.2013.03.035

Dinkard, W., Jr, Long, M.O., Goozner, R.E., 1998. Recycling of CIS Photovoltaic Waste. US Patent 5, 779,877. Washington, D.C.: U.S.

Eberspacher, C., Fthenakis, V.M., 1997. Disposal and recycling of end-of-life PV modules. IEEE Photovoltaic Specialists Conference. 1067-1072. doi:10.1109/PVSC.1997.654272

Ekmekçioğlu, M., Kaya, T., Kahraman, C., 2010. Fuzzy multicriteria disposal method and site selection for municipal solid waste. Waste Manage. 30, 1729-1736. doi:10.1016/j.wasman.2010.02.031

Erkut, E., Karagiannidis, A., Perkoulidis, G., Tjandra, S.A., 2008. A multicriteria facility location model for municipal solid waste management in North Greece. Eur. J. Oper. Res. 187, 1402-1421. doi:10.1016/j.ejor.2006.09.021

European Parliament and of the Council, 2003. On waste electrical and electronic equipment (WEEE).

Fisher, J.B., Trulio, L.A., Biging, G.S., Chromczak, D., 2007. An Analysis of Spatial Clustering and Implications for Wildlife Management: A Burrowing Owl Example. Environ. Manage. 39, 403-411. doi:10.1007/s00267-006-0019-y

Food and Agriculture Organization of the United Nations, 1998. Sources of International Water Law (No. 65). Rome.

Frisson, L., Lieten, K., Bruton, T., Declercq, K., 2000. Recent improvements in industrial PV module recycling. 16th European Photovoltaic Solar Energy Conference 1-4.

Fthenakis, V.M., 2000. End-of-life management and recycling of PV modules. Energy Policy 28, 1051-1058. doi:10.1016/S0301-4215(00)00091-4

Funabashi, T., 2011. A GIS Approach for Estimating Optimal Sites for Grid-Connected Photovoltaic (PV) Cells in Nebraska. Honors Thesis. University of Nebraska-Lincoln. Gemitzi, A., Tsihrintzis, V.A., Voudrias, E., Petalas, C., Stravodimos, G., 2006. Combining 
DO NOT DISTRIBUTE. COPY OF MANUSCRIPT UNDER REVIEW.

geographic information system, multicriteria evaluation techniques and fuzzy logic in siting MSW landfills. Environ. Geol. 51, 797-811. doi:10.1007/s00254-006-0359-1

Goe, M., Gaustad, G., 2014a. Strengthening the case for recycling photovoltaics: An energy payback analysis. Appl. Energ. 120, 41-48.

Goe, M., Gaustad, G., 2014b. Identifying critical materials for photovoltaics in the US: A multimetric approach. Appl. Energ. 123, 387-396.

Goozner, R., Long, M.O., Dinkard, W., Jr, 1999. Recycling of CdTe Photovoltaic Waste. US Patent 5,897,685. Washington, D.C.: U.S.

Gorsevski, P.V., Donevska, K.R., Mitrovski, C.D., Frizado, J.P., 2012. Integrating multi-criteria evaluation techniques with geographic information systems for landfill site selection: A case study using ordered weighted average. Waste Manage. 32, 287-296. doi:10.1016/j.wasman.2011.09.023

Graedel, T.E., 2011. On the Future Availability of the Energy Metals. Annu. Rev. Mater. Res. 41, 323-335. doi:10.1146/annurev-matsci-062910-095759

Guiqin, W., Li, Q., Guoxue, L., Lijun, C., 2009. Landfill site selection using spatial information technologies and AHP: A case study in Beijing, China. J. Environ. Manage. 90, 2414-2421. doi:10.1016/j.jenvman.2008.12.008

Ham, Y.J., Maddison, D.J., Elliott, R.J.R., 2013. The valuation of landfill distances in Birmingham. Ecol. Econ. 85, 116-129. doi:10.1016/j.ecolecon.2012.09.006

Hofierka, J., Kaňuk, J., 2009. Assessment of photovoltaic potential in urban areas using opensource solar radiation tools. Renew. Energ. 34, 2206-2214.

doi:10.1016/j.renene.2009.02.021

Hokkanen, J., Salminen, P., 1997. Choosing a solid waste management system using multicriteria decision analysis. Eur. J. Oper. Res. 98, 19-36.

Hu, T.L., Sheu, J.B., Huang, K.H., 2002. A reverse logistics cost minimization model for the treatment of hazardous wastes. Transp. Res. Part E-Log. 38, 457-473.

Huld, T., Š́ri, M., 2003. GIS-based estimation of solar radiation and PV generation in central and eastern Europe on the web. 9th EC GI \& GIS Workshop 1-8.

Kan, C.C., Lee, P.-F., Wen, T.-H., Chao, D.Y., Wu, M.H., Lin, N.H., Huang, S.Y., Shang, C.-S., Fan, I.C., Shu, P.Y., 2008. Two clustering diffusion patterns identified from the 2001-2003 dengue epidemic, Kaohsiung, Taiwan. Am. J. Trop. Med. Hyg. 79, 344-352. 
DO NOT DISTRIBUTE. COPY OF MANUSCRIPT UNDER REVIEW.

Kao, J.J., Lin, Hung-Yue, 1996. Multifactor spatial analysis for landfill siting. J. Environ. Eng.ASCE 122(10), 902-908.

Karagiannidis, A., Moussiopoulos, N., 1998. A model generating framework for regional waste management taking local peculiarities explicitly into account. Locat. Sci. 6, 281-305.

Kirca, Ö., Erkip, N., 1988. Selecting transfer station locations for large solid waste systems. Eur. J. Oper. Res. 35, 339-349.

Kobos, P., Erickson, J., Drennen, T., 2006. Technological learning and renewable energy costs: implications for US renewable energy policy. Energy Policy 34, 1645-1658. doi:10.1016/j.enpol.2004.12.008

Kollikkathara, N., Feng, H., Yu, D., 2010. A system dynamic modeling approach for evaluating municipal solid waste generation, landfill capacity, and related cost management issues. Waste Manage. 30, 2194-2203. doi:10.1016/j.wasman.2010.05.012

Kontos, T.D., Komilis, D.P., Halvadakis, C.P., 2003. Siting MSW landfills on Lesvos Island with a GIS-based methodology. Waste Manage. Res. 21, 262-277. doi:10.1177/0734242X0302100310

Korucu, M.K., Karademir, A., 2013. Siting a Municipal Solid Waste Disposal Facility, Part Two: The Effects of External Criteria on the Final Decision. J. Air Waste Manage. Assoc. 64, 131-141. doi:10.1080/10962247.2013.809388

Kouznetsova, M., Huang, X., Ma, J., Lessner, L., Carpenter, D.O., 2006. Increased Rate of Hospitalization for Diabetes and Residential Proximity of Hazardous Waste Sites. Environ. Health Perspect. 115, 75-79. doi:10.1289/ehp.9223

Lai, P.C., Wong, C.M., Hedley, A.J., Lo, S.V., Leung, P.Y., Kong, J., Leung, G.M., 2004. Understanding the Spatial Clustering of Severe Acute Respiratory Syndrome (SARS) in Hong Kong. Environ. Health Perspect. 112, 1550-1556. doi:10.1289/ehp.7117

Li, B., Du, H.Z., Ding, H.J., Shi, M.Y., 2011. E-Waste Recycling and Related Social Issues in China. Energy Procedia 5, 2527-2531. doi:10.1016/j.egypro.2011.03.434

Lin, Hung-Yueh, Kao, J.-J., 1999. Enhanced spatial model for landfill siting analysis. J. Environ. Eng. 125, 845-851.

Lober, D.J., 2008. Why Not Here? The Importance of Context, Process, and Outcome on Public Attitudes Toward Siting of Waste Facilities. Soc. Natur. Resour. 9, 375-394.

Marwede, M., Berger, W., Schlummer, M., Mäurer, A., Reller, A., 2013. Recycling paths for 
DO NOT DISTRIBUTE. COPY OF MANUSCRIPT UNDER REVIEW.

thin-film chalcogenide photovoltaic waste - Current feasible processes. Renew. Energ. 55, 220-229. doi:10.1016/j.renene.2012.12.038

Müller, A., Wambach, K., Alsema, E.A., 2006. Life Cycle Analysis of Solar Module Recycling Process. Materials Research Society Symposium Proceedings 895, 1-6.

Nassar, N.T., Barr, R., Browning, M., Diao, Z., Friedlander, E., Harper, E.M., Henly, C., Kavlak, G., Kwatra, S., Jun, C., Warren, S., Yang, M.-Y., Graedel, T.E., 2012. Criticality of the Geological Copper Family. Environ. Sci. Technol. 46, 1071-1078. doi:10.1021/es203535w

National Renewable Energy Laboratory, 2015. The Open PV Project [WWW Document]. openpv.nrel.gov. URL (accessed 3.24.15).

Nema, A.K., Gupta, S.K., 1999. Optimization of regional hazardous waste management systems: an improved formulation. Waste Manage. 19, 441-451.

Nnorom, I.C., Osibanjo, O., 2008. Electronic waste (e-waste): Material flows and management practices in Nigeria. Waste Manage. 28, 1472-1479. doi:10.1016/j.wasman.2007.06.012

Noll, D., Dawes, C., Rai, V., 2014. Solar Community Organizations and active peer effects in the adoption of residential PV. Energy Policy 1-14. doi:10.1016/j.enpol.2013.12.050

Osibanjo, O., Nnorom, I.C., 2007. The challenge of electronic waste (e-waste) management in developing countries. Waste Manage. Res. 25, 489-501. doi:10.1177/0734242X07082028

Peiró, L.T., Méndez, G.V., Ayres, R.U., 2013. Material Flow Analysis of Scarce Metals: Sources, Functions, End-Uses and Aspects for Future Supply. Environ. Sci. Technol. 47, 2939-2947. doi:10.1021/es301519c

Perpiña, C., Martínez-Llario, J.C., Pérez-Navarro, Á., 2013. Multicritiera assessment in GIS environments for siting biomass plants. Land Use Policy 31, 326-335. doi:10.1016/j.landusepol.2012.07.014

Rai, V., McAndrews, K., 2012. Decision-making and behavior change in residential adopters of solar PV, in: Presented at the Proceedings of the World Renewable Energy Conference, Denver.

Ramirez-Rosado, I.J., Fernandez-Jimenez, L.A., Monteiro, C., Garcia-Garrido, E., ZorzanoSantamaria, P., 2011. Spatial long-term forecasting of small power photovoltaic systems expansion. Renew. Energ. 36, 3499-3506. doi:10.1016/j.renene.2011.05.037

Raugei, M., Fthenakis, V.M., 2010. Cadmium flows and emissions from CdTe PV future expectations. Energy Policy 38, 5223-5228. doi:10.1016/j.enpol.2010.05.007 
DO NOT DISTRIBUTE. COPY OF MANUSCRIPT UNDER REVIEW.

Robinson, S.A., Stringer, M., Rai, V., Tondon, A., 2013. GIS-Integrated Agent-Based Model of Residential Solar PV Diffusion, in:. Presented at the 32nd United States Association of Energy Economics (USAEE)/ International Association of Energy Economics (ISEE) North American Conference, Anchorage.

Schelly, C., 2014. Implementing renewable energy portfolio standards: The good, the bad, and the ugly in a two state comparision. Energy Policy 67, 543-551.

doi:10.1016/j.enpol.2013.11.075

Sharifi, M., Hadidi, M., Vessali, E., Mosstafakhani, P., Taheri, K., Shahoie, S., Khodamoradpour, M., 2009. Integrating multi-criteria decision analysis for a GIS-based hazardous waste landfill sitting in Kurdistan Province, western Iran. Waste Manage. 29, 2740-2758. doi:10.1016/j.wasman.2009.04.010

Siddiqui, M.Z., Everett, J.W., Vieux, B.E., 1996. Landfill siting using geographic information systems: a demonstration. J. Environ. Eng.-ASCE 122, 515-523.

Smith, M.J.D., Goodchild, M.F., Longley, P., 2007. Geospatial Analysis: A Comprehensive Guide to Principles, Techniques, and Software Tools, 1st ed. Trobadour Publishing Ltd., United Kingdom.

Sumathi, V.R., Natesan, U., Sarkar, C., 2008. GIS-based approach for optimized siting of municipal solid waste landfill. Waste Manage. 28, 2146-2160. doi:10.1016/j.wasman.2007.09.032

Şener, B., Süzen, M.L., Doyuran, V., 2005. Landfill site selection by using geographic information systems. Environ. Geol. 49, 376-388. doi:10.1007/s00254-005-0075-2

Tiba, C., Candeias, A.L.B., Fraidenraich, N., Barbosa, E.M. de S., de Carvalho Neto, P.B., de Melo Filho, J.B., 2010. A GIS-based decision support tool for renewable energy management and planning in semi-arid rural environments of northeast of Brazil. Renew. Energ. 35, 2921-2932. doi:10.1016/j.renene.2010.05.009

Toyota Industrial Equipment, 2014. Toyota Forklifts and Trucks [WWW Document]. toyotaforklift.com. URL (accessed 6.24.14).

US Geological Survey, 2012. Mineral Commodity Summaries 2012, US Geological Survey. United States Internal Trade Commission, 2013. Used Electronic Products: An Examination of U.S. Exports (No. 4379).

US Environmental Protection Agency, 1991. Material Recovery Facilities for Municipal Solid 
DO NOT DISTRIBUTE. COPY OF MANUSCRIPT UNDER REVIEW.

Waste Handbook (No. EPA/625/6-91/031). US Environmental Protection Agency, Washington, D.C.

US Environmental Protection Agency, 2009. Municipal Solid Waste Generation, Recycling, and Disposal in the United States: Facts and Figures for 2008, 1-12.

Vardimon, R., 2011. Assessment of the potential for distributed photovoltaic electricity production in Israel. Renew. Energ. 36, 591-594. doi:10.1016/j.renene.2010.07.030

Vrijheid, M., 2000. Health effects of residence near hazardous waste landfill sites: a review of epidemiologic literature. Environ. Health Persp. 108(Suppl 1), 101.

W.W. Grainger Inc, 2014. Grainger Conveyors and Conveyor Systems [WWW Document]. grainger.com. URL (accessed 6.24.14).

Wang, T.-Y., Hsiao, J.-C., Du, C.-H., 2012. Recycling of materials from silicon base solar cell module, in: Presented at the 38th IEEE Photovoltaic Specialists Conference, IEEE, Austin, pp. 002355-002358.

Yamashita, K., Miyazawa, A., Sannomiya, H., 2006. Research and Development on Recycling and Reuse Treatment Technologies for Crystalline Silicon Photovoltaic Modules, in:. Presented at the IEEE 4th World Conference on Photovoltaic Energy Conversion, Waikoloa, pp. 2254-2257.

Yildiz, E.D., Ünlü, K., Rowe, R.K., 2004. Modelling Leachate Quality and Quantity in Municipal Solid Waste Landfills. Waste Manage. Res. 22, 78-92.

doi:10.1177/0734242X04043937 